\title{
An electrochemical method for determination of the standard Gibbs energy of anion transfer between water and n-octanol
}

\author{
Rubin Gulaboski, Valentin Mirčeski ${ }^{1}$, Fritz Scholz ${ }^{*}$ \\ Institut für Chemie und Biochemie, Ernst-Moritz-Arndt-Universität Greifswald, Soldmannstraße 23, Greifswald D-17489, Germany
}

Received 20 December 2001; received in revised form 23 January 2002; accepted 24 January 2002

\begin{abstract}
The transfer of the ions $\mathrm{Cl}^{-}, \mathrm{Br}^{-}, \mathrm{I}^{-}, \mathrm{ClO}_{4}^{-}, \mathrm{SCN}^{-}, \mathrm{NO}_{3}^{-}, \mathrm{BF}_{4}^{-}$, and $\left(\mathrm{C}_{6} \mathrm{H}_{5}\right)_{4} \mathrm{~B}^{-}$across the water $\mid n$-octanol $(\mathrm{W} \mid \mathrm{OC})$ liquid interface was studied and the standard Gibbs energies of ion transfer were determined. The ion transfer was achieved by oxidation of decamethylferrocene dissolved in a droplet of $n$-octanol that was attached to a graphite electrode immersed in the aqueous solutions of the respective alkali salts of the anions. The electrode reaction can be described by the equation: $\mathrm{dmfc}_{(\mathrm{OC})}+\mathrm{X}_{(\mathrm{W})}^{-} \rightleftarrows \mathrm{dmfc}_{(\mathrm{OC})}^{+}+$ $\mathrm{X}_{(\mathrm{OC})}^{-}+\mathrm{e}^{-}$, where $\mathrm{X}^{-}$is the transferred anion. Square-wave voltammetry at this three-phase arrangement was utilised to determine the formal potential of the decamethylferrocene/decamethylferrocenium $\left(\mathrm{dmfc} / \mathrm{dmfc}^{+}\right)$couple under the condition of ion transfer across the water $n$-octanol interface. For calibration the standard Gibbs energies of ion transfer have been extrapolated to octanol from the series of known data for methanol, ethanol, $n$-propanol, and $n$-butanol. All these data are consistent and the experimental dependence of the formal potentials on the standard Gibbs energies is as predicted by theory. The validity of data is further supported by calculations of Gibbs energies of ion transfer using the Born theory. Until now it was not possible to perform electrochemical measurements at the water $\mid n$-octanol interface because in the conventional four-electrode cells this interface cannot be polarised. With the new method it is now for the first time possible to determine the Gibbs energies of transfer of ions across the water $\mid n$-octanol interface. These values are of very wide use for assessing the lipophilicity of compounds in chemistry, medicine, and pharmacology. @ 2002 Elsevier Science B.V. All rights reserved.
\end{abstract}

Keywords: Water-n-octanol partition; Ion transfer; Voltammetry; Decamethylferrocene

\section{Introduction}

The hydrophobicity (liphophilicity) is a very significant parameter used in different areas of chemistry, medicine, and pharmacology for predicting the transport through membranes, interactions with biological receptors and enzymes, toxicity and biological effects in general [1-3]. Among numerous two-phase liquid systems that have been studied so far to evaluate the liphophilicity of compounds, the water/n-octanol system is of particular importance and indeed it became the standard system. The water $/ n$-octanol partition coefficients, which are related to the standard Gibbs energies

\footnotetext{
${ }^{*}$ Corresponding author. Tel.: +3834-86-4450; fax: +3834-86-4451. E-mail address: fscholz@mail.uni-greifswald.de (F. Scholz).

${ }^{1}$ On leave from: Faculty of Natural Sciences and Mathematics, Institute of Chemistry, "Sv. Kiril i Metodij” University, P.O. Box 162, 1000 Skopje, Republic of Macedonia.
}

of transfer, are measures of the hydrophobicity of compounds, which in many cases correlate well with the above-mentioned chemical and biological properties. Furthermore, the water $/ n$-octanol partition coefficients help to predict the binding of various physiologically active compounds to proteins and to purified enzymes [4].

When charged species are transferred between two immiscible solvents, electrochemical methods are extremely suitable to study the hydrophobicity because the transfer of ions is an electrochemical process involving chemical and electric work. Recently Girault and coworkers [5-8] used ion partition diagrams for presentation of the lipophilicity of a compound as a function of $\mathrm{pH}$ and the liquid|liquid interfacial potential. The standard potentials of ion transfer have been calculated from the experimental half-wave potentials of the iontransfer voltammograms in the conventional four-electrode cells at the interface of two immiscible solutions. 
However, with this experimental arrangement the water/ $n$-octanol system is not accessible, since the water $\mid n$ octanol interface cannot be polarised sufficiently to allow studies of the ion transfer reactions. For this reason, so far there have not been determined any data of the standard Gibbs energies of ion transfer for water $/ n$ octanol.

To overcome some of the limitations of the conventional methods to study the ion transfer at interfaces of immiscible solutions (ITIES), recently a novel experimental methodology has been established [9-11]. According to the employed voltammetric method, a droplet of a water-immiscible organic solvent containing an electrochemically active compound, e.g. decamethylferrocene, is attached to a graphite electrode and immersed into an aqueous electrolyte solution. The electrochemical reaction of the electroactive compound starts along the three-phase junction line as recently confirmed by microelectrode measurements [12]. As the organic phase does not contain any deliberately dissolved electrolyte, the electrode reactions are accompanied by an ion transfer across the liquid|liquid interface in order to preserve the electroneutrality of the organic phase. This scenario requires that the standard Gibbs energy of transfer of the electrochemically formed ion (e.g. $\mathrm{dmfc}^{+}$) for the transfer from the organic solvent to the aqueous solution is larger than that value for the charge compensating anions for the transfer from water to the organic phase. The voltammetric response depends on the electron transfer reaction, confined mainly to the three-phase boundary region and the ion transfer across the liquid|liquid interface. With this simple experimental set-up, the ion transfer processes can be examined utilising a standard three-electrode potentiostat. Moreover the potential window is extended considerably, as the organic phase does not contain any dissolved electrolyte.

In the present communication, the study of ion transfer reactions of a series of inorganic ions across the water $n$-octanol interface is presented. The ion transfer reactions are electrochemically driven by the electrode reaction of the decamethylferrocene/decamethylferrocenium $\left(\mathrm{dmfc} / \mathrm{dmfc}^{+}\right)$couple. It is demonstrated that the employed methodology provides an exciting possibility to estimate the standard Gibbs free energies of ion transfer across the water $\mid n$-octanol interface by a simple and fast procedure.

\section{Experimental}

A $0.05 \mathrm{~mol} \mathrm{dm}^{-3}$ solution of $\mathrm{dmfc}$ was prepared by dissolving in water saturated 1-octanol (n-octanol), which was the product of Acros Organics (USA). A drop of this solution, with a volume of $2 \mu \mathrm{l}$ was attached to the surface of a paraffin impregnated graphite elec- trode (PIGE) by help of an Eppendorf-type pipette. The PIGE was a graphite rod with $0.5 \mathrm{~cm}$ diameter and an exposed electrode surface area of $0.2 \mathrm{~cm}^{2}$. The radius of the hemispherical droplet was about $0.15 \mathrm{~cm}$. During square-wave voltammetric experiments, neither a significant distortion nor a change of the colour of the droplet has been observed. The dimension of the droplet influences only the measured currents, whereas both the position of the response (peak potential) and shape (half-peak width) are not affected.

Square-wave voltammograms were recorded using the electrochemical measuring system $\mu$ AUTOLAB (Eco-Chemie, Utrecht, Netherlands). An $\mathrm{Ag}|\mathrm{AgCl}|$ saturated $\mathrm{NaCl}$ solution reference electrode $(E=0.200 \mathrm{~V}$ vs. SHE) was used and a platinum wire served as auxiliary electrode. All salts used for preparation of the supporting electrolytes were used as purchased. The preparation of PIGEs is described elsewhere [13]. All chemicals used were of analytical grade. The water used was Millipore Q. Water was saturated with $n$-octanol and $n$-octanol was saturated with water. All experiments were carried out at room temperature of about $20^{\circ} \mathrm{C}$.

\section{Results and discussion}

The oxidation of $\mathrm{dmfc}$ to $\mathrm{dmfc}^{+}$in the three-phase arrangement, $n$-octanol $\mid$ electrode $\mid$ water $(\mathrm{OC}|\mathrm{E}| \mathrm{W})$, gives rise to a well-defined SW voltammetric response with a peak potential depending on the anions in the aqueous phase. Fig. 1 shows the SWV responses recorded in the 1 $\mathrm{mol} \mathrm{dm}{ }^{-3}$ aqueous solution of $\mathrm{KCl}, \mathrm{KBr}$, and $\mathrm{KI}$. Regardless of the composition of the aqueous medium, the oxidation of dmfc in the three-phase arrangement is a reversible electrode process. As depicted in Fig. 2, the forward (oxidation) and backward (reduction) components of the SWV response are bell-shaped curves with equal peak heights and peak potentials. By increasing the SW signal frequency from 30 to $350 \mathrm{~Hz}$ the half-peak width and peak potential of the response remained virtually unchanged. Over the exploited frequency interval the half-peak width and peak potentials are scattered around the average value within \pm 8 and $\pm 10 \mathrm{mV}$, respectively, confirming the reversibility of the electrode mechanism.

Being linearly dependent on the concentration of anions present in the aqueous phase, the peak potential of the SWV response shifts towards more negative potentials by an increase of the concentration of anions. For instance, in the case of iodide ions, the relationship $E_{\mathrm{p}}$ vs. $\log \left(c_{\mathrm{I}^{-}(\mathrm{W})}\right)$ has a slope of $-60 \mathrm{mV}$, indicating that a transfer of anions from water to the organic phase accompanies the oxidation of $\mathrm{dmfc}$ in the three-phase arrangement. Thus the overall electrode process of $\mathrm{dmfc}$ oxidation in the $\mathrm{OC}|\mathrm{E}| \mathrm{W}$ three-phase arrangement can be described by the following reaction: 


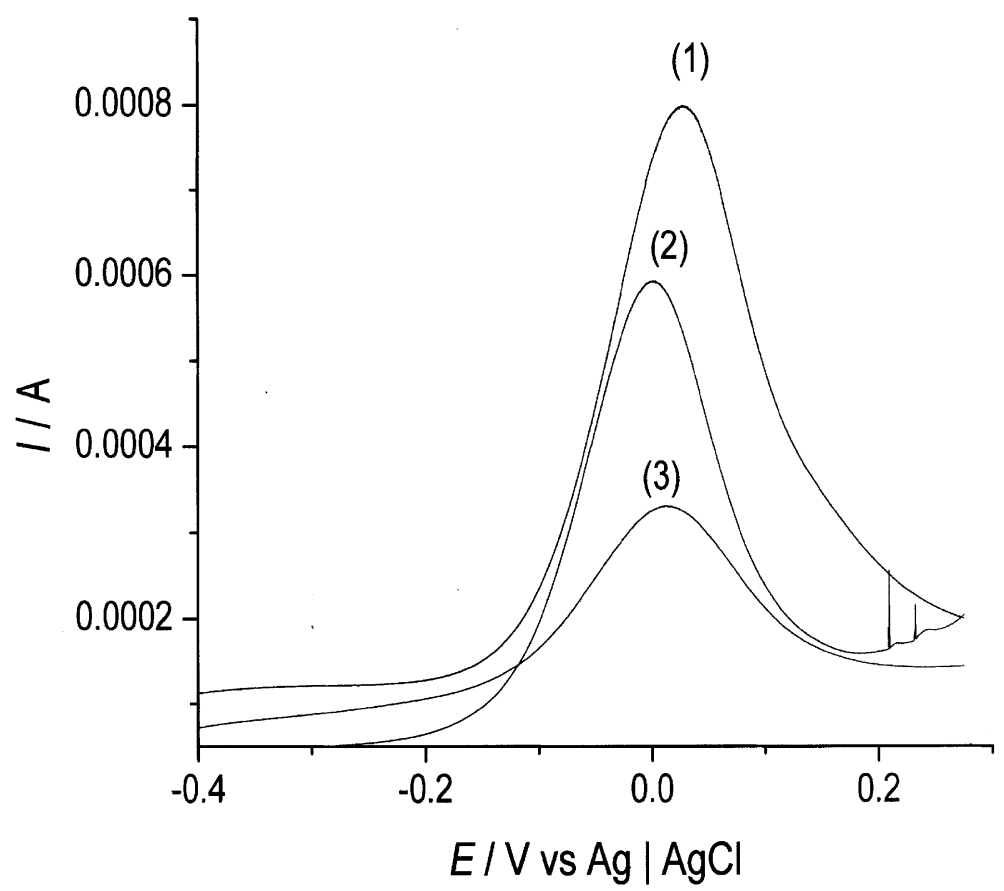

Fig. 1. SW voltammetric response of an $n$-octanol droplet containing $0.05 \mathrm{~mol} \mathrm{dm}{ }^{-3} \mathrm{dmfc}$ attached to a paraffin impregnated graphite electrode, which is immersed in $1 \mathrm{~mol} \mathrm{dm}^{-3}$ aqueous solution of $\mathrm{KCl}(1), \mathrm{KI}(2)$, and $\mathrm{KBr}$ (3). The experimental conditions were: SW frequency $f=100 \mathrm{~Hz}$, SW amplitude $E_{\mathrm{sw}}=50 \mathrm{mV}$, scan increment $\mathrm{d} E=0.15 \mathrm{mV}$, and starting potential $E_{\mathrm{s}}=-0.40 \mathrm{~V}$.

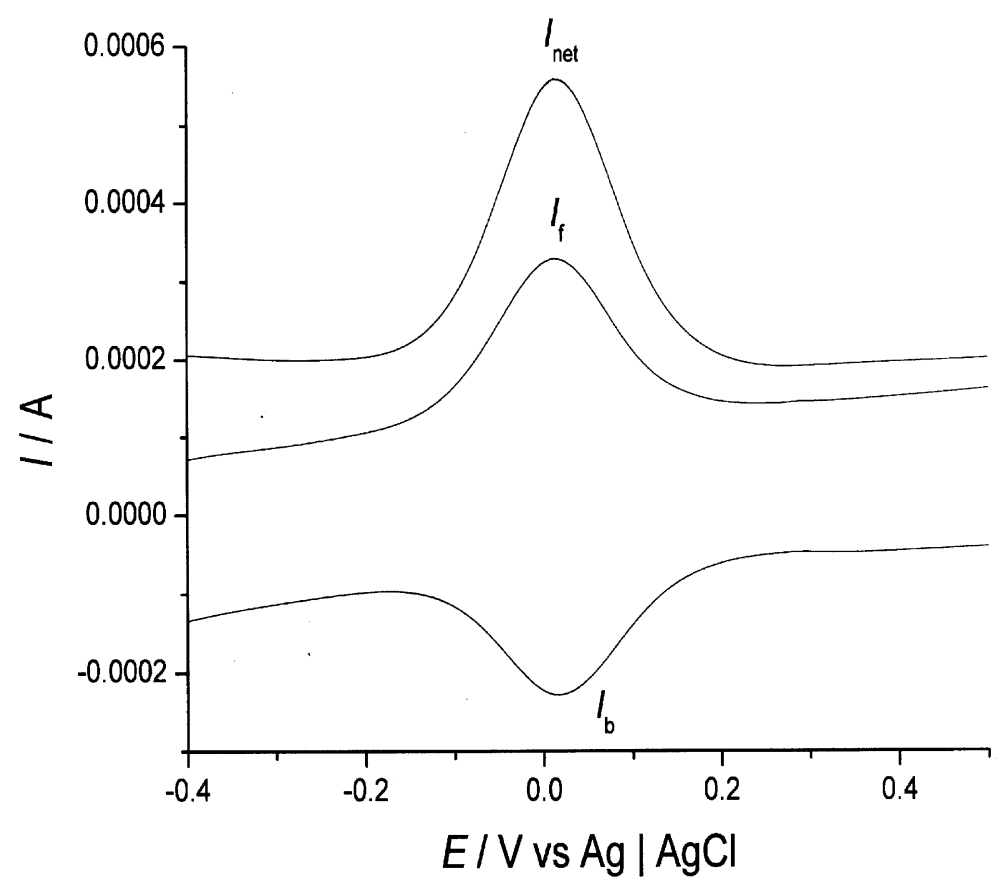

Fig. 2. Forward $\left(\mathrm{I}_{\mathrm{f}}\right)$, backward $\left(\mathrm{I}_{\mathrm{b}}\right)$, and net-SW $\left(\mathrm{I}_{\text {net }}\right)$ components of the square-wave voltammetric response of an $n$-octanol droplet containing 0.05 mol dm${ }^{-3} \mathrm{dmfc}$ attached to a paraffin impregnated graphite electrode which is immersed in $1 \mathrm{~mol} \mathrm{dm}^{-3} \mathrm{KBr}$ aqueous solution. The experimental conditions were same as in Fig. 1.

$\mathrm{dmfc}_{(\mathrm{OC})}+\mathrm{X}_{(\mathrm{W})}^{-} \leftrightarrows \mathrm{dmfc}_{(\mathrm{OC})}^{+}+\mathrm{X}_{(\mathrm{OC})}^{-}+\mathrm{e}^{-}$

Scheme 1 depicts the situation at the electrode.
This proposed electrode mechanism is identical with that observed when nitrobenzene was used as an organic medium in a previous study [9]. The thermodynamic 


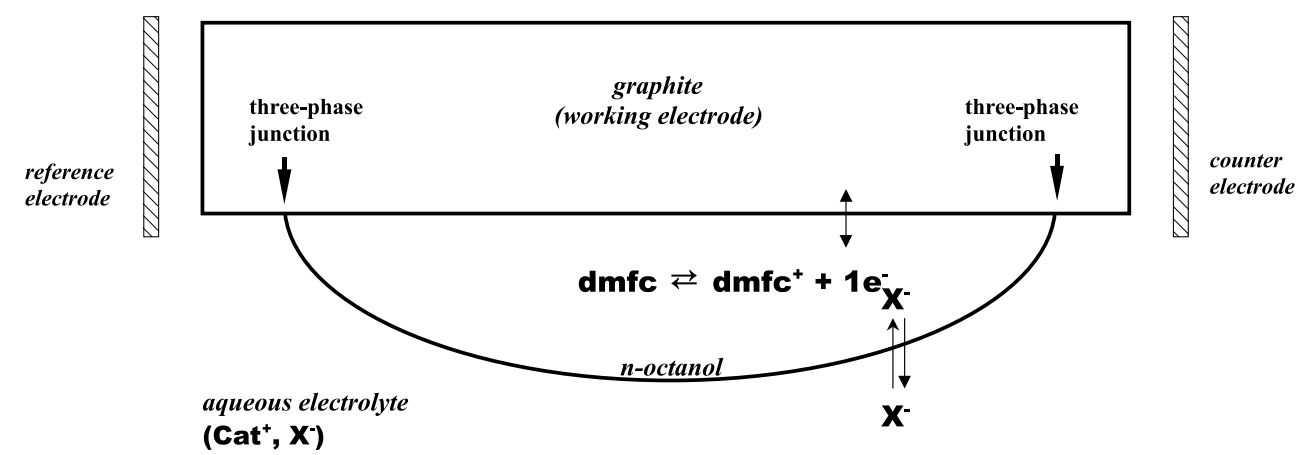

Scheme 1. Schematic situation of the three-phase arrangement on the electrode (for explanation see the text).

treatment of reaction (I) gives the following form of the Nernst equation:

$E=E_{\mathrm{c}}^{\theta^{\prime}}+\frac{R T}{F} \ln \frac{a_{\mathrm{dmfc}^{+}(\mathrm{OC})}}{a_{\mathrm{dmfc}(\mathrm{OC})}}$,

where the formal potential $E_{\mathrm{c}}^{\theta^{\prime}}$ follows the dependence:

$$
\begin{aligned}
E_{\mathrm{c}}^{\theta^{\prime}}= & E_{\mathrm{dmfc}_{(\mathrm{OC})}^{\theta} \mid \operatorname{dmfc}_{(\mathrm{OC})}}^{\theta}+\Delta_{\mathrm{W}}^{\mathrm{OC}} \varphi_{\mathrm{X}^{-}}^{\theta}-\frac{R T}{F} \ln \left(a_{\mathrm{X}_{(\mathrm{W})}^{-}}\right) \\
& +\frac{R T}{F} \ln \left(a_{\mathrm{dmfc}_{(\mathrm{OC})}}^{*} / 2\right) .
\end{aligned}
$$

Here, $E_{\mathrm{dmfc}_{(\mathrm{OC})}^{+}}^{\theta} \mid \mathrm{dmfc}_{(\mathrm{OC})}$ is the standard redox potential of the $\mathrm{dmfc}^{+} / \mathrm{dmfc}$ couple in $n$-octanol, $\Delta_{\mathrm{w}}^{\mathrm{OC}} \varphi_{\mathrm{X}^{-}}^{\theta}$ is the standard potential of the transfer of $\mathrm{X}^{-}$from water to $n$ octanol, and $a_{\mathrm{dmfc}}^{*}$ is the initial activity of dmfc in the organic phase. As the peak potential of the SWV response is equivalent to the formal potential of the redox reaction when the electrode mechanism is reversible [14], the latter equation can be used to estimate the standard potential of ion transfer from water to $n$-octanol. Knowing the standard transfer potential of the anion, one can calculate the standard Gibbs energy of transfer across the water $\mid n$-octanol interface using the equation [15]:

$\Delta_{\mathrm{w}}^{\mathrm{oc}} \varphi_{\mathrm{X}^{-}}^{\theta}=-\frac{\Delta_{\mathrm{w}}^{\mathrm{oc}} G_{\mathrm{X}^{-}}^{\theta}}{z F}$

(for mono-valent anions, $z$ is -1 ).

For this purpose, one needs the standard redox potential of the $\mathrm{dmfc}^{+} / \mathrm{dmfc}$ couple in $n$-octanol, which unfortunately was unknown. Moreover it seems rather difficult to measure accurately this value due to expected interferences by the liquid-junction potential.

To solve this problem, an attempt was made to estimate the standard Gibbs energies of transfer of halide ions on the basis of an extrapolation, using the corresponding values of the Gibbs energies of transfer from water to other $n$-aliphatic alcohols, which have been determined by means of solubility measurements [16]. Fig. 3 represents a correlation diagram of the standard Gibbs energies of transfer of chloride, bromide, and iodide ions measured in methanol, ethanol, $n$-propanol,

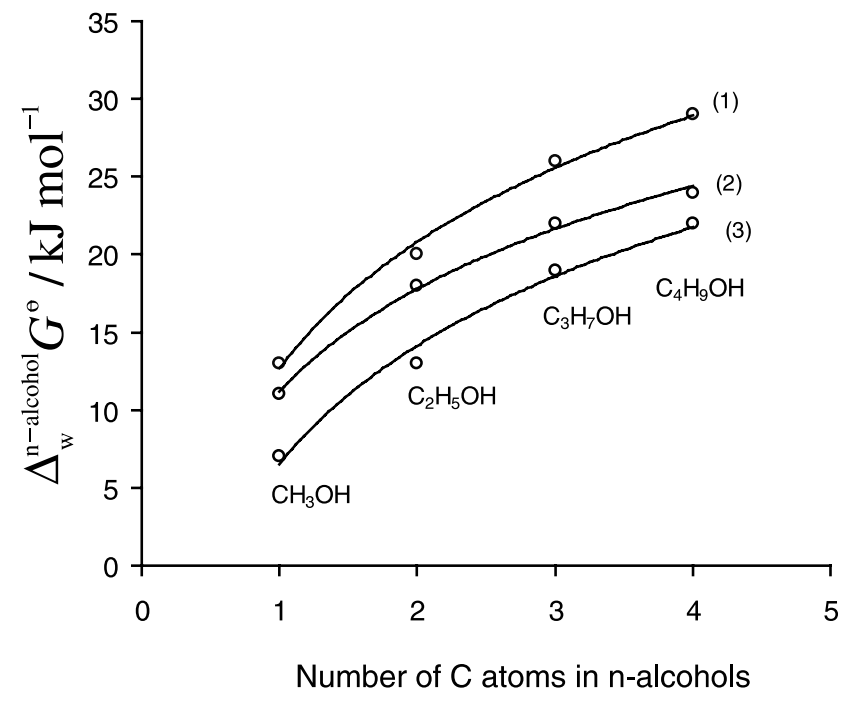

Fig. 3. The correlation of the standard Gibbs free energies of transfer of chloride (1), bromide (2), and iodide ions (3) from water to methanol, ethanol, $n$-propanol, and $n$-butanol with the number of C-atoms in the corresponding alcohol. The data are taken from [15].

and $n$-butanol with the number of $\mathrm{C}$-atoms of the corresponding alcohol. Applying a least-squares regression analysis using a logarithmic function, the best fitting was achieved with the following equations:

$$
\begin{aligned}
& \Delta_{\mathrm{W}}^{\mathrm{OC}} G_{\mathrm{Cl}^{-}}^{\theta} / \mathrm{kJ} \mathrm{mol}^{-1}=11.725 \ln \left(N_{\mathrm{C}}\right)+12.686 \\
& \quad\left(R^{2}=0.9937\right), \\
& \Delta_{\mathrm{W}}^{\mathrm{OC}} G_{\mathrm{Br}^{-}}^{\theta} / \mathrm{kJ} \mathrm{mol}^{-1}=9.526 \ln \left(N_{\mathrm{C}}\right)+11.181 \\
& \quad\left(R^{2}=0.9964\right), \\
& \Delta_{\mathrm{W}}^{\mathrm{OC}} G_{\mathrm{I}^{-}}^{\theta} / \mathrm{kJ} \mathrm{mol}^{-1}=10.992 \ln \left(N_{\mathrm{C}}\right)+6.516 \\
& \quad\left(R^{2}=0.9868\right)
\end{aligned}
$$

for chloride, bromide and iodide, respectively. Here $N_{\mathrm{C}}$ is the number of $\mathrm{C}$-atoms in the particular alcohol. By substituting for $N_{\mathrm{C}}=8$ in Eq. (4) the estimated standard Gibbs free energy of the transfer of chloride ions from water to $n$-octanol is $\Delta_{\mathrm{W}}^{\mathrm{OC}} G_{\mathrm{Cl}^{-}}^{\theta}=36.96 \mathrm{~kJ} \mathrm{~mol}^{-1}$. With the aid of Eq. (3) the standard Gibbs free energy of 
Table 1

Estimated values of the standard potential of ion transfer $\Delta_{\mathrm{W}}^{\mathrm{OC}} \varphi_{\mathrm{X}^{-}}^{\theta}(\mathrm{V})$ from water to $n$-octanol for halide ions on the base of extrapolation of the functions presented in Fig. 3 combined with the peak potential of the SWV response of the reaction (I) measured in $1 \mathrm{~mol} \mathrm{dm}^{-3}$ aqueous KX solution, where $\mathrm{X}$ is a symbol for $\mathrm{Cl}^{-}, \mathrm{Br}^{-}$, and $\mathrm{I}^{-}$ions

\begin{tabular}{clllll}
\hline Ion & $E_{\mathrm{p}}(\mathrm{V})$ & $\begin{array}{l}\Delta_{\mathrm{W}}^{\mathrm{OC}} \varphi_{\mathrm{X}^{-}}^{\theta}(\mathrm{V}) \\
\text { Extrapolation with } \\
\text { chloride ions }\end{array}$ & $\begin{array}{l}\Delta_{\mathrm{W}}^{\mathrm{OC}} \varphi_{\mathrm{X}^{-}}^{\theta}(\mathrm{V}) \\
\text { Extrapolation with } \\
\text { bromide ions }\end{array}$ & $\begin{array}{l}\Delta_{\mathrm{W}}^{\mathrm{OC}} \varphi_{\mathrm{X}^{-}}^{\theta}(\mathrm{V}) \\
\text { Extrapolation with } \\
\text { iodide ions }\end{array}$ & $\begin{array}{l}\Delta_{\mathrm{W}}^{\mathrm{OC}} \varphi_{\mathrm{X}^{-}}^{\theta}(\mathrm{V}) \\
\text { Average values }\end{array}$ \\
\hline $\mathrm{Cl}^{-}$ & 0.031 & 0.383 & 0.358 & 0.337 & 0.360 \\
$\mathrm{Br}^{-}$ & 0.017 & 0.369 & 0.344 & 0.323 & 0.345 \\
$\mathrm{I}^{-}$ & 0.001 & 0.353 & 0.328 & 0.307 & 0.329 \\
\hline
\end{tabular}

transfer is represented in a form of a standard potential difference at the water $n$-octanol interface for chloride ions, $\Delta_{\mathrm{w}}^{\mathrm{oc}} \varphi_{\mathrm{Cl}^{-}}^{\theta}=0.383 \mathrm{~V}$. Knowing the standard potential of transfer of chloride ions together with the formal potential of the reaction (I) measured in $1 \mathrm{~mol} \mathrm{dm}^{-3}$ $\mathrm{KCl}$ aqueous solution $\left(E_{\mathrm{c}}^{\theta^{\prime}}=0.031 \mathrm{~V}\right.$ vs. $\left.\mathrm{Ag} \mid \mathrm{AgCl}\right)$, as a first approximation the standard redox potential of the $\mathrm{dmfc}^{+} / \mathrm{dmfc}$ couple in $n$-octanol is

$E_{\text {dmfc }_{(\mathrm{Cl})}^{+} / \mathrm{dmfc}_{(\mathrm{Cl})}}^{\theta}=-0.259 \mathrm{~V}$

vs. $\mathrm{Ag} \mid \mathrm{AgCl}$. Thus, as the standard potential of the electron transfer is known, the standard potential of the transfer of bromide and iodide ions can be calculated. The same procedure has been repeated starting from the extrapolated data for bromide and iodide ions. All the data collected with this procedure are summarised in Table 1.

The average values of the standard potential of transfer from water to $n$-octanol of the halide ions, estimated by combining the extrapolated data with the formal potential of the reaction (I), are listed in the last column of Table 1 . To verify the validity of the obtained data, the formal potential of reaction (I) is plotted versus the average values of the standard potentials of ion transfer (see Fig. 4). The dependence is linear, with a correlation coefficient of the regression line $R^{2}=0.9996$ and a slope of 0.97 , which is in fairly good agreement with Eq. (2). The intercept of the line in Fig. 4 is -0.317 $\mathrm{V}$ (vs. $\mathrm{Ag} \mid \mathrm{AgCl}$ ), which corresponds to the standard redox potential of $\mathrm{dmfc}^{+} / \mathrm{dmfc}$ couple in $n$-octanol based on the averaged values for the three halide ions.

Alternatively, the energies of the ion transfer from water to $n$-octanol of halide ions can be calculated on the basis of the classical electrostatic Born theory. According to the Born electrostatic solvation model, the ion is considered as a sphere a given radius $r$ immersed in a continuous medium of with a dielectric constant $\varepsilon$. The transfer energy, i.e. resolvatation energy, is obtained as a difference between electrostatic energies for charging the ion up to $z e$, in the organic and aqueous medium

$\Delta_{\mathrm{w}}^{\mathrm{oc}} G_{\mathrm{Born}}^{\theta}=-\frac{N_{\mathrm{A}} z^{2} e^{2}}{8 \pi \varepsilon_{0} r}\left(\frac{1}{\varepsilon_{(\mathrm{w})}}-\frac{1}{\varepsilon_{(\mathrm{o})}}\right)$.

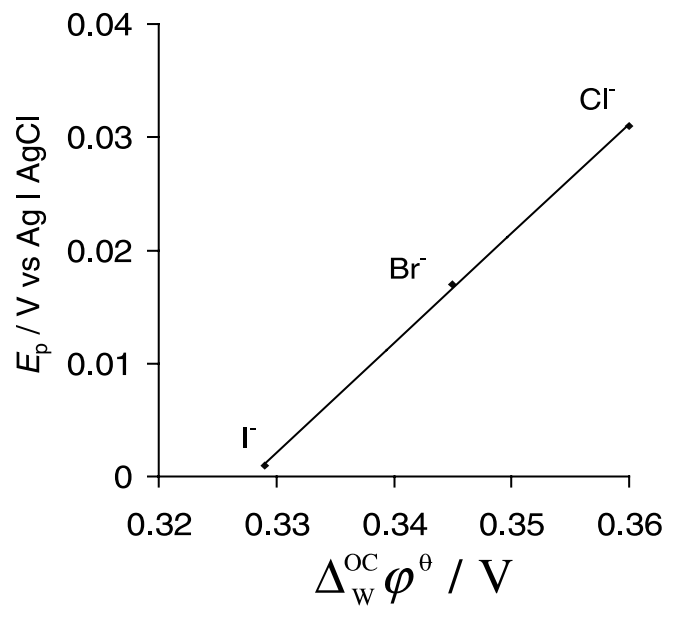

Fig. 4. The dependence of the peak potential of the SWV response of reaction (I) measured in the presence of $1 \mathrm{~mol} \mathrm{dm}^{-3}$ aqueous solution of $\mathrm{KCl}, \mathrm{KBr}$, and $\mathrm{KI}$ on the average values for the standard potential of transfer across water $n$-octanol interface of halide ions. The other experimental conditions are same as in Fig. 1.

Here, $N_{\mathrm{A}}$ is Avogadro's constant, $\varepsilon_{0}$ is the permittivity of vacuum, $\varepsilon_{(\mathrm{w})}$ and $\varepsilon_{(\mathrm{o})}$ are dielectric constants of water and organic medium, respectively, $e$ is the elementary charge, and $z$ is the number of elementary charges of the ion. It is well known that the Born theory does not consider short-range interactions of the ion with the solvent, and thus it is only an approximate approach for calculating the standard Gibbs energy of transfer. However, there has not been yet derived an analytical expression based on more accurate quantum mechanical considerations, which can replace Eq. (7).

The data used for calculations together with the estimated values of the standard Gibbs energies of transfer from water to $n$-octanol of the halide ions are listed in Table 2. Fortunately, the data estimated on the basis of the Born theory and those estimated previously are in very good agreement. Fig. 5 shows the correlation between these two sets of data, having a correlation coefficient of $R^{2}=0.9982$, and thus supporting the validity of the estimated data. Therefore, it can be considered that the estimated values of the standard potential of $\mathrm{dmfc}^{+} / \mathrm{dmfc}$ couple in $n$-octanol 
Table 2

Estimated values of the standard Gibbs energies of transfer and corresponding standard potentials of ion transfer from water to $n$-octanol of halide ions on the basis of electrostatic Born theory using Eq. (4)

\begin{tabular}{llll}
\hline Ion & $\begin{array}{l}\text { Ionic radii } \\
(\mathrm{m})\end{array}$ & $\begin{array}{l}\Delta_{\mathrm{W}}^{\mathrm{OC}} \varphi_{\mathrm{X}^{-}}^{\theta} \\
(\mathrm{V})\end{array}$ & $\begin{array}{l}\Delta_{\mathrm{W}}^{\mathrm{OC}} G_{\mathrm{Born}}^{\theta} \\
(\mathrm{kJ} \mathrm{mol}\end{array}$ \\
\hline $\mathrm{Cl}^{-}$ & $1.81 \times 10^{-10}$ & 0.370 & 36.000 \\
$\mathrm{Br}^{-}$ & $1.96 \times 10^{-10}$ & 0.340 & 33.300 \\
$\mathrm{I}^{-}$ & $2.20 \times 10^{-10}$ & 0.310 & 29.600 \\
\hline
\end{tabular}

The other data for calculations were: permittivity of vacuum $\varepsilon_{0}=8.85 \times 10^{-12} \mathrm{~F} \mathrm{~m}^{-1}$, dielectric constant of water $\varepsilon_{\mathrm{W}}=80 \mathrm{~F} \mathrm{~m}^{-1}$, dielectric constant of octanol $\varepsilon_{\mathrm{oc}}=10 \mathrm{~F} \mathrm{~m}^{-1}$, and elementary charge $e=1.602 \times 10^{-19} \mathrm{C}$.

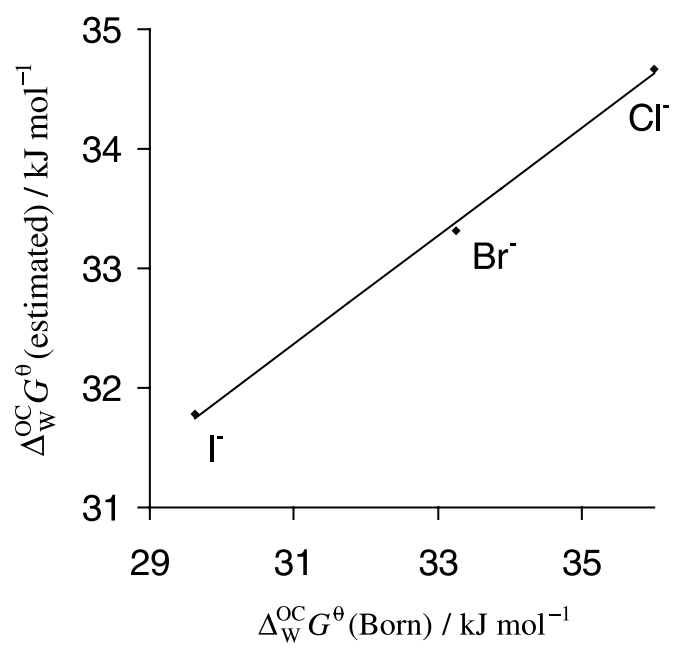

Fig. 5. The correlation of the standard Gibbs energies of transfer from water to $n$-octanol for halide ions calculated on the base of electrostatic Born theory with those estimated by extrapolation.

$E_{\mathrm{dmfc}_{(\mathrm{OC})}^{+} / \mathrm{dmfc}_{(\mathrm{OC})}}^{\theta}=-0.317 \mathrm{~V}$

vs. $\mathrm{Ag} \mid \mathrm{AgCl}$ are correct, and it can be used further to calculate the standard Gibbs free energies of transfer of other ions accompanying the oxidation of $\mathrm{dmfc}$ in $n$ octanol.

The SWV response of dmfc oxidation in the threephase boundary when the aqueous phase contained $\mathrm{ClO}_{4}^{-}, \mathrm{NO}_{3}^{-}, \mathrm{SCN}^{-}, \mathrm{BF}_{4}^{-}$, and $\left(\mathrm{C}_{6} \mathrm{H}_{5}\right)_{4} \mathrm{~B}^{-}$ions is depicted in Fig. 6. The data for the peak potentials measured in the presence of these anions, together with estimated values for standard Gibbs free energies, are listed in Table 3. The calculations have been carried out with the aid of Eq. (2).

It is important to emphasise that the thiocyanate ions are characterised by a lower energy of transfer from water to $n$-octanol than perchlorate ions, which is a rather unusual finding in comparison with the corresponding data for nitrobenzene or dichlorethane. However, the same difference was observed for ethanol [16], which supports the validity of the data collected by the current method.

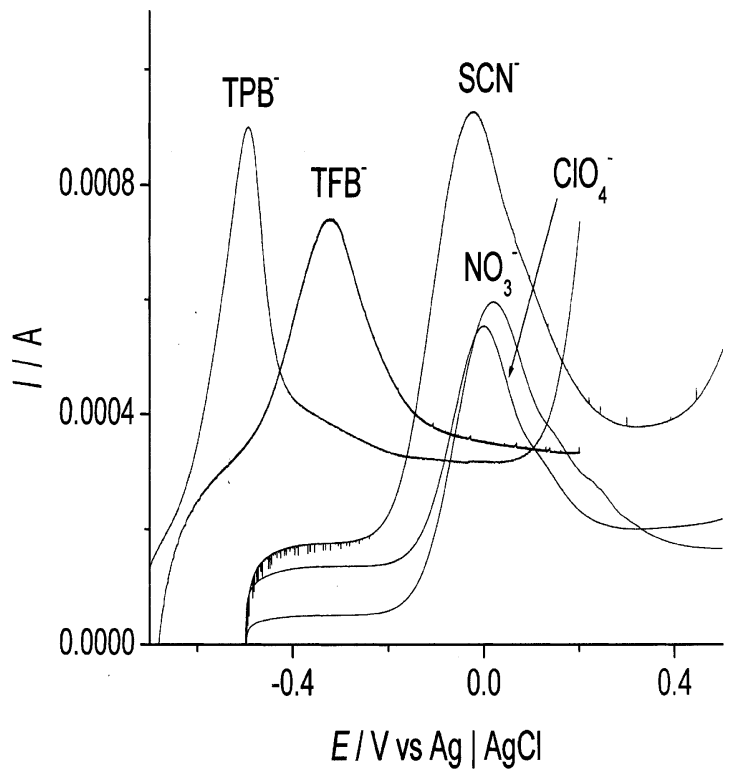

Fig. 6. SW voltammetric responses of an $n$-octanol droplet containing $0.05 \mathrm{~mol} \mathrm{dm}^{-3} \mathrm{dmfc}$ attached to a paraffin impregnated graphite electrode, which is immersed in $1 \mathrm{~mol} \mathrm{dm}^{-3}$ aqueous solution of $\left(\mathrm{C}_{6} \mathrm{H}_{5}\right)_{4} \mathrm{~B}^{-}$(TPB), $\mathrm{BF}_{4}^{-}$(TFB), $\mathrm{ClO}_{4}^{-}, \mathrm{NO}_{3}^{-}$, and $\mathrm{SCN}^{-}$. The other experimental conditions are the same as in Fig. 1.

Table 3

Estimated values of the standard Gibbs free energies and corresponding standard potentials of transfer from water to $n$-octanol of a series of anions

\begin{tabular}{llll}
\hline $\begin{array}{l}\text { Anion } \\
\left(c_{\mathrm{X}-(\mathrm{W})}=1 \mathrm{~mol} \mathrm{dm}^{-3}\right)\end{array}$ & \multicolumn{1}{l}{$\begin{array}{l}E_{\mathrm{p}} \\
(\mathrm{V})\end{array}$} & \multicolumn{1}{c}{$\begin{array}{l}\Delta_{\mathrm{W}}^{\mathrm{OC}} \varphi_{\mathrm{X}^{-}}^{\theta} \\
(\mathrm{V})\end{array}$} & \multicolumn{1}{c}{$\begin{array}{l}\Delta_{\mathrm{W}}^{\mathrm{OC}} G_{\mathrm{X}^{-}}^{\theta} \\
\left(\mathrm{kJ} \mathrm{mol}^{-1}\right)\end{array}$} \\
\hline $\mathrm{TPB}^{-}$ & -0.473 & -0.160 & -15.510 \\
$\mathrm{TFB}^{-}$ & -0.332 & -0.015 & -1.491 \\
$\mathrm{SCN}^{-}$ & -0.029 & 0.297 & 28.650 \\
$\mathrm{ClO}_{4}^{-}$ & 0.000 & 0.327 & 31.530 \\
$\mathrm{NO}_{3}^{-}$ & 0.021 & 0.348 & 33.618 \\
\hline
\end{tabular}

The calculations have been carried out using Eq. (2). The standard redox potential of the $\mathrm{dmfc}^{+} / \mathrm{dmfc}$ couple is $E_{\mathrm{dmfc}_{(\mathrm{OC})}^{+} / \mathrm{dmfc}_{(\mathrm{OC})}}=$ $-0.317 \mathrm{~V}$ vs. $\mathrm{Ag} \mid \mathrm{AgCl}$. TPB and TFB are abbreviations for tetraphenylborate and tetrafluoroborate ions, respectively. The experimental conditions are the same as for Fig. 6 .

\section{Conclusion}

To the best of our knowledge, this is the first experimental report of an electrochemical method to study the ion transfer across the water $\mid n$-octanol interface. Utilising a simple experimental arrangement, the employed method enables accessing the standard Gibbs free energies of ion transfer from water to $n$-octanol of anions. The employed methodology can be extended to study the hydrophobicity of various anionic species in the water $/ n$-octanol system, which are of particular importance for different areas of chemistry, medicine, and pharmacology. 


\section{Acknowledgements}

V. Mireski thanks A.V. Humboldt-Stiftung for provision of a Humboldt fellowship, R. Gulaboski thanks Deutscher Akademischer Austauschdienst (DAAD) for provision of a $\mathrm{PhD}$ scholarship, and F. Scholz acknowledges kind support by Deutsche Forschungsgemeinschaft (DFG) and Fonds der Chemischen Industrie (FCI).

\section{References}

[1] A.G. Volkov, Liquid Interfaces in Chemical Biological and Pharmaceutical Applications, Marcel Dekker, New York, Basel, 2001.

[2] Handbook of Chemical Property Estimation, American Chemical Society, Washington, DC, 1990.

[3] C. Hansch, J.E. Quinlan, G.L. Lawrence, J. Org. Chem. 33 (1968) 347.

[4] C. Hansch, Acc. Chem. Res. 2 (1969) 232.
[5] F. Reymond, P.A. Carrupt, H.H. Girault, J. Electroanal. Chem. 449 (1998) 49.

[6] F. Reymond, G. Lagger, P.A. Carrupt, H.H. Girault, J. Electroanal. Chem. 451 (1998) 59.

[7] F. Reymond, D. Fermin, H.J. Lee, H.H. Girault, Electrochim. Acta 45 (2000) 2647.

[8] F. Reymond, P.A. Carrupt, B. Testa, H.H. Girault, Eur. J. Chem. 5 (1999) 39.

[9] F. Scholz, S. Komorsky-Lovrić, M. Lovrić, Electrochem. Commun. 2 (2000) 122.

[10] Š. Komorsky-Lovrić, M. Lovrić, F. Scholz, J. Electroanal. Chem. 508 (2001) 129.

[11] Š. Komorsky-Lovrić, M. Lovrić, F. Scholz, Collect. Czech. Chem. Commun. 66 (2001) 434.

[12] M. Donten, Z. Stojek, F. Scholz, Electrochem. Commun. (in press).

[13] F. Scholz, B. Meyer, in: A.J. Bard, I. Rubinstein (Eds.), Electroanalytical Chemistry, A Series of Advances, 20, Marcel Dekker, New York, 1998, p. 1.

[14] J. Osteryoung, J.J. O'Dea, in: A.J. Bard (Ed.), Electroanalytical Chemistry, 14, Marcel Dekker, New York, 1986, p. 209.

[15] H.H Girault, D.J. Schiffrin, in: A.J. Bard (Ed.), Electroanalytical Chemistry, 15, Marcel Dekker, New York, 1989.

[16] Y. Marcus, Ion Properties, Marcel Dekker, New York, 1997. 